Portland State University

PDXScholar

5-24-2017

\title{
The Use and Implementation of Body-Worn Cameras in Policing
}

Drew A. Beglau

Portland State University

Follow this and additional works at: https://pdxscholar.library.pdx.edu/honorstheses Let us know how access to this document benefits you.

\section{Recommended Citation}

Beglau, Drew A., "The Use and Implementation of Body-Worn Cameras in Policing" (2017). University Honors Theses. Paper 407.

https://doi.org/10.15760/honors.403

This Thesis is brought to you for free and open access. It has been accepted for inclusion in University Honors Theses by an authorized administrator of PDXScholar. Please contact us if we can make this document more accessible: pdxscholar@pdx.edu. 
The Use and Implementation of Body-Worn Cameras in Policing

by

Drew Beglau

\author{
An undergraduate thesis submitted in partial fulfillment of the \\ requirements for the degree of \\ Bachelor of Science \\ in \\ University Honors \\ and \\ Criminology \& Criminal Justice
}

Mark Harmon-Leymon

Portland State University

2017 


\begin{abstract}
:
There are few studies revolving the effects, benefits, and negatives influences of body-worn cameras. However, the purpose of this paper is to address these few studies, dissect the results, and come to a general conclusion of what purposes body-worn cameras serve in today's law enforcement, government, and the general public. The overall goal of the paper is to determine the extent and nature of nation-wide use of bodyworn cameras, and what studies have found in regards to effect and influence on the community and on law enforcement.
\end{abstract}

\title{
Introduction:
}

The use of body cameras in policing is a relatively new concept in the work of law enforcement across the nation. Dash cameras have been in use comparably longer but are still a newer technology that is not yet widely used outside large police departments. While technology has advanced at an exponential rate in the last few decades, so have the methods of policing and the technology used in law enforcement. While there are many electronics used in policing that are relatively uncontroversial, such as radios for communication and computer technology inside police vehicles, body-mounted cameras have been a heated topic of debate in the time since they were introduced for many reasons, including privacy violations, cost, and extensive training for law enforcement, among other things.

Many law enforcement agencies across the nation are either seriously considering or already using camera technology. Some police agencies are making the use of the technology mandatory, while some want nothing to do with it. The diverse opinions 
revolving the use of body-worn cameras, or BWCs, are highly complicated, mainly because there are multiple stances taken on their use. It is not simply a matter of making these cameras a new mandatory piece of equipment for law enforcement, but a highly complex system involving many players, and many unanswered questions regarding the constitutionality and cost-effectiveness. Some of the problems surrounding the implementation of the cameras focus on individual privacy rights and the question of whether to record all interactions with the public, or keep the taping selective. Many argue that it is a violation of privacy rights, which is a particularly complicated part of the body-worn camera debate. Others claim that the use of the technology is an effective way to hold law enforcement accountable, while those opposing say it is another way for police agencies to become corrupt. These concerns will be addressed in the thesis by collecting literary support and previous research conducted on the sensitive topic of body-worn cameras. This includes peer-reviewed articles, news articles, organization standpoints, like police agencies and citizen-organized groups, and official research conducted by government agencies, such as the Department of Justice and local police departments.

\section{Discourse Community:}

Questions beg, who is interested in this issue, and who does it affect? What purpose does this research serve, and where does this research come from? The main addressees of this paper are the United States as a whole, and other parts of the world as an audience. More specifically, police agencies, public groups, and U.S. government agencies like the Department of Justice. The issues surrounding BWCs and the impact it has on police-community relations is pertinent to their investigations and daily 
operations, mainly because it involves delicate privacy issues and police legitimacy. The research being conducted and the evidence taken from that research serves to answer the question of the thesis and delve into what can or should be done based on the impact the use of BWCs have on the relationship between the public and law enforcement. Without this research, and without this question to be answered, there is no in-depth analysis of the true affects the technology has.

The public as a whole as well as law enforcement and higher government should all be concerned about the impact BWCs have on the community, and the trust that is established between law enforcement and the public. The relationship between the two is highly important for a fully functioning government and a politically and socially content community. Trust in the government and its agencies is vital in supporting a properly working police force and establishing a fair criminal justice system.

\section{Methods:}

The methods that will be used to collect evidence supporting the thesis from multiple angles will be primarily literature of- peer-reviewed articles- and news reports revolving around the use of body and dash cameras in policing. While the technology is relatively new, there are still a variety of previous works on the issue, including peerreviewed articles, which will serve as the main source of support.

The goal of the research is to identify the positive and negative aspects of BWCs in policing, dissect the policies surrounding the implementation of the technology, and reveal evidence that supports or does not support the use of cameras in law enforcement for the future. It is a goal to examine specific cases in which body or dash cameras 
strengthened or weakened the interaction between police and the public, and whether those cases support the use of the technology or reveal it's ineffectiveness.

Goals of the collection of data through the above sources include but are not limited to:

1. Identifying strengths in the use of body-worn camera technology

2. Identifying weaknesses in the use of body-worn camera technology

3. Law enforcement support of body-worn cameras

4. Community support of body-worn cameras

5. Specific cases in which the use of body-worn cameras affected the relationship between the community and law enforcement

6. Issues with recording under certain circumstances

7. Privacy laws/policies in place regarding the use of body-worn cameras

8. Possible policies or policy revisions that could improve the use of the technology

9. Determining whether the new technology could benefit law enforcement or if it should be removed

\section{Body:}

Firstly, we must examine a general overview of the use of BWCs in today's society on a national level. The complexity of the issue is the relative differences in opinions and policies surrounding the use of BWCs in policing. That is to say, some areas of the United States are supportive of the technology, and others have negative reactions 
to the implementation of policy surrounding it. Body-worn cameras is a sensitive topic, but highly relative to current law enforcement issues around the United States.

Little research has been conducted on the exact number of law enforcement agencies that use the technology, mainly because the technology is new and adapting to current issues. Research shows that the United Kingdom experimented with the use of body-worn cameras as early as 2003, but limited research has been conducted in the United States. It is noted that in 2013, a survey conducted on nearly 500 law enforcement agencies revealed that roughly $25 \%$ used BWCs (U.S. DOJ, 2015). The technology has grown in both popularity and efficiency since that time, four years ago. As an emerging technology, BWCs have gained credibility among law enforcement due to the spread of studies showing the benefits to agencies and communities around the world, and as a result, an increasing number of police agencies are using them (White, 2014). There is currently a survey underway that will better grasp the true number of law enforcement agencies that have adopted a BCW policy or program, but that data is not yet available.

In contrast, there are many cities across the United States that have established BWC policies and have been operating under them for years. More specifically, data has been collected on law enforcement in Los Angeles, California, and Phoenix, Arizona regarding their use of BWCs. Furthermore, studies in California, Texas, Washington D.C., Arizona, and Washington are gaining widespread attention (Katz, 2014). We will go into further detail on these evaluations later in the paper.

There are numerous positive and negative perceptions on the use of body-worn and dash cameras. Some of the benefits to using the technology include increased police 
accountability, transparency, legitimacy, improved citizen behavior and actions toward police, faster resolution of complaints, increased evidence for arrests, and decreases in complaints against law enforcement. In contrast, some of the negative effects of bodyworn and dash cameras include a concern over officer and citizen privacy rights, the extensive training needed for the implementation of such a new technology, and the debate over where data should be downloaded and the time limitations surrounding downloads (White, 2014).

Perhaps most importantly, the implementation of body-worn cameras has increased the transparency and accountability of officers. Not only has the technology helped reduce confrontations between the public and officers, it has also reduce conflict between officers (Miller, 2014). Police departments that have adopted the use of BWCs and dash cameras hope to increase police legitimacy by being open with the public about issues among the community involving law enforcement, however there is little research to support this goal (White, 2014).

"Everyone is on their best behavior when the cameras are running. The officers, the public-everyone." (Miller, 2014). This belief that cameras will encourage those recorded to be on their "best behavior" is quite common among law enforcement agencies that are already using or looking to use BWC technology. It has been found that shifts without the use of BWCs experienced twice as many use-of-force incidences than shifts that were using the technology (White, 2014). This could suggest that officers are more aware of their behavior, whether it is appropriate or not, while using BWCs and could ultimately lead to fewer use-of-force incidents. Because use-of-force is often a sensitive topic for law enforcement and the community, implementing the use of BWCs 
may act as a positive mediator to allow the public to feel less physically threatened by law enforcement regardless of whether the officer(s) are threatening or not.

Much of the public has been in favor of the use of BWCs in policing, for many of the reasons law enforcement is starting to introduce them in everyday activities. According to a recent online Cato/YouGov poll, 92\% of Americans somewhat support or strongly support the implementation of BWCs. Furthermore, a majority, 55\%, would be willing to pay extra taxes to fund the purchase of the technology for law enforcement agencies (Cato Institute, 2015). It is noted that supporting the use of something is not necessarily related to the willingness to pay for it out of one's own pocket, but in this instance, it is shown that a majority of the public is generally supportive of paying taxes for BWCs. A further breakdown of the numbers represented in the survey found that $60 \%$ strongly supported the use of BWCs and 32\% somewhat supported it, once again proving a majority of the population is in favor of the technology.

A prominent factor weighing in support of BWCs is the idea that they will protect police officers and citizens. There is much concern over the "corruption" of law enforcement and the mistrust between the community and police officers. The 2015 online Cato/YouGov poll also enquired about who or what the public thought BWCs would protect if they were used regularly and/or within their community. $9 \%$ answered they would only protect the police, $10 \%$ said it would only protect the citizens who interact with law enforcement, but a vast majority, $81 \%$, said they believed it would equally protect both groups (Cato Institute, 2015). This is an important factor to consider when deciding whether a police department should use BWCs, mainly because the goal of using the technology is to increase trust between both groups, not just one or the other. 
If a particular group was benefitting from the use of BWCs more than another, it may decrease trust of the other group and cause a growth of conflict.

BWCs also provide hard video and audio evidence in any cases that may need to reviewed later on, and provide documentation of certain events that occurred that may lead to an arrest. Studies have found that footage from an incident can be used by officers to gather accurate data and properly document crimes, and cases were far less likely to go to trial. Not only this, but officers were found to spend less time filling out paperwork and were able to patrol more due to having convenient footage to go over for their records (White, 2014). This is incredibly beneficial to police departments in that it can reduce the amount of time spent recording crimes and increase the time spent patrolling. Furthermore, it relieves strain on the prosecution and defense in cases because it can reduce the number of cases that go to trial and the lengthy process before. Positive results have also come from domestic violence cases with reluctant victims, as the video footage often provides an immediate after-the-fact account of the event, such as the demeanor of the accused and the emotional upset of the victim (White, 2014).

With all new technology in the realm of law enforcement, there are many critics and concerns over the constitutionality and policy. One of the most common concerns is that the use of BWCs is a violation of privacy. Many groups have argued that recording citizens would violate federal and state laws pertaining to a person's reasonable expectation of privacy. Not only is it a federal law, but many states also have varying rules about when it is acceptable to record. Many states require a two-party consent before recording private conversations. This does not just apply to video footage, but also audio recording. The idea of video-only footage has been proposed in policing, but others 
argue it defeats the purpose of providing sound evidence of an incident or event that has occurred during a police-citizen interaction (White, 2014).

It is noted further that individuals who associate with certain groups may be unwilling, hesitant, or scared to provide information to the police if they know the interaction has been recorded. Critics also contend that sensitive situations, in which victims are in need of medical care, or are traumatized, may be stressed further after finding out they have been recorded (White, 2014).

Not only are skeptics concerned about the privacy of citizens, but they also note that police officer's privacy may be jeopardized. Some concern surrounds when the officers need to use the restroom or are on breaks, and the proposal was that they would be able to shut off the recording device during that time. However, from this suggestion rises skepticism that the officers would then have the ability to shut off the device at their discretion, which means they would have the choice to record an interaction or not. There has been some negative response to the implementation of BWCs by police officers, claiming that the footage would be used to scrutinize every aspect of the officer's duties as well as be an attempt to find any sort of misconduct and penalize the officers. Others have argued that it is a major change in the procedures of their job and should be discussed further before making it a mandatory part of their duties (White, 2014).

Besides privacy concerns, there are some minor hazards officers may face when using BWCs. From the less threatening, like a sore neck and headaches from using the headbands, to major, like assailants using the wires to strangle officers, or officers at risk of assault for simply using the technology. Not many studies have been conducted on the 
health and safety risks officers face when using BWCs, but it is a concern that has been expressed by BWC critics.

Regarding the video footage itself, many skeptics have raised questions on the time that will be spent downloading and reviewing footage, as well as the resources and financial investment that must be put into storing data. Most obviously is the initial cost of the devices to be fitted on officers, but financial costs become steep once the footage is gathered and must be reviewed and stored. In 2015, the acting Chief of the Phoenix Police estimated it would cost close to $\$ 3.5$ million to provide cameras and hardware to it's 3,000 officers, which is not including the storage and IT support needed to manage the data later on (BJA, 2015). Critics ask whether all recorded interactions will be kept and whether it would be efficient to save all data due to storage costs, or just those that captured a serious offense or resulted in a complaint against the officer. This question can also lead to other concerns about who decides what footage is to be kept, and for how long, and to what extent resources will be needed to review the footage (White, 2014).

On a related topic to the resources that must be invested, there is also a great concern over the training and policy that will surround the use of the technology. While financial resources are a concern for the initial cost of equipment, training sessions will also cost police departments, and possibly taxpayers, a large sum of money. The part of the public that is against the use of BWCs are certainly not keen on paying for the technology out of their own pocket, which may cause further strain on the relationship between law enforcement and the community if legislation is passed for a tax increase for BWCs. Furthermore, many people are concerned about the lack of policy surrounding 
BWCs and are urging law enforcement to invest more time on proper training and improving policy (White, 2014).

This concern leads to another leading interest in who the footage will be available to. Many civil rights groups argue that the data must be made available to the public immediately. Texas signed Senate Bill 158 effective in September of 2015 encompassing the use of BWCs that outraged many groups, mainly because of the rules involved in the use of the technology. Specifically, that any footage involving a highly sensitive incident, such as use of deadly force or relates to a criminal investigation of an officer may not be released to the public after the conclusion of criminal or administrative proceedings. Another part of the new Texas policy is that law enforcement may release footage to the public, but is not necessarily required to (Equal Future, June 2015). Members of Equal Future group claimed this would contradict the goal of transparency between law enforcement and the community, and allowed officers too much discretion in choosing what to record and release to the public.

A heated topic regarding BWC footage is whether or not police officers should be allowed to view the footage before making their statement. There are mixed reactions to this idea, with opposing sides claiming it would be an outlet for corruption and allow officers to change their story and break rules without repercussion. In general, police unions and departments are in favor of the proposed policy while civil rights groups oppose, mainly because the groups believe officers will have an unfair advantage in being allowed to view the footage before making a report. A Cato/YouGov poll revealed that the general public is divided quite equally on this topic, with $52 \%$ saying police offices should be allowed to view footage beforehand and roughly $48 \%$ disagreeing (Cato 
Institute, 2015). The goal of this policy would ultimately be to assist officers in making a more accurate and detailed account of the event, but many think this is misguided. Arguments against the policy include that video footage from a BWC provides one perspective and can be misleading, and to base a report on a single account would be inaccurate and unfair. Other concerns include that the previewing results in "cross contamination" of testimony given by witnesses, that it enables lying, and that it undermines the legitimacy of investigations (Stanley, J., \& Bibring, P., 2015). It has also been noted that if a police officer is allowed to view the footage before making a statement, the person filing a complaint should also be able to, or neither should. The main concern regarding pre-review of data is that it would create an unfair advantage for the viewing party, and therefore should be made a policy for both parties, or neither. A solution that has been proposed to this issue is that officers would need to make an initial statement, then be allowed to watch the footage and add an additional follow-up section to their original report (Shepard, 2017). This proposal has seemingly had positive reactions from the general public.

Questions from the concerned public also surround whether the technology will allow for officers and police departments to become corrupt and misleading, due to the power they might have over the cameras, such as deciding what to record, when to record, and manipulating data. Many firmly believe BWCs are simply another outlet for law enforcement to manipulate the system. Those who are unsupportive of BWCs used in law enforcement have stated that "body-worn cameras start from a position of mistrust", and that wearing a camera does not automatically create a sense of trust between police officers and community members (BJA, 2015). 


\section{Examples/policies implemented}

Earlier in the paper, we discussed some specific places in the United States that have implemented the use of BWC and dash cameras and have established policies over the course of time they have been in use. Like many policies surrounding new ideas, they change and adapt with the growth of technology and the ever-changing laws of the criminal justice system. Some of the places that have conducted studies or have implemented new or controversial policies surrounding BWCs include California, Seattle, Washington, Washington D.C., Arizona, and Texas.

First, we will discuss the use of BWCs in Phoenix, Arizona. The Phoenix Police Department (PPD) urged the use of the BWCs for many of the same reasons that police departments across the nation are beginning to use them - which includes increasing police accountability, establishing trust between the community and law enforcement, and more specific to Phoenix, to increase the effectiveness of responding to domestic violence disputes. The Bureau of Justice Assistance (BJA) awarded the PPD with money so that they could purchase the technology. Fifty-six officers were fitted with body cameras. The evaluation began in April of 2013, and would continue for a year. The study also focused on the officer's opinions of the BWCs (Katz, 2014). The research conducted revealed a positive influence on police officers, the community, and the courts for numerous reasons. Mainly, it reduced complaints against the police significantly as well as increased the number of arrests. The complaints that were filed against officers who wore body cameras were also more likely to be thrown out compared to complaints filed against officers who were not wearing the body cameras (Katz, 2014). This pattern has been shown in many studies conducted on specific precincts implementing the use of 
body cameras. It's importance rests in the accountability of officers as well as the community-police relationship. Moreover, the use of BWCs proved beneficial to the pursuit of domestic violence cases. The video evidence was incredibly helpful for prosecution to pursue a legitimate case, and resulted in higher numbers of charges against offenders and guilty pleas and verdicts (Katz, 2014).

Another in-depth study was conducted in Rialto, California. The Rialo Police department services nearly 100,000 residents and has roughly 115 sworn police officers. The experiment was the result of a collaboration between the police department and TASER International, Inc that fitted the officers with high-tech body cameras. The experiment involved control groups and experimental groups of officers who were instructed in different ways pertaining to their BWCs. Specifically, one group was told to record all interactions with the public, while the other was instructed to not record any interactions whatsoever. The results were shocking. It was found that by using the BWCs, use-of-force incidents declined by 59\%, and citizens' complaints were reduced by over 87\% between 2012-2013. Not only this, but the footage collected also reduced litigation costs and other court-related costs due to providing reliable evidence (Ramirez). The Rialto study has been used as supportive evidence that BWCs are beneficial and, if properly organized and regulated with policy, can be a valuable tool for law enforcement agencies and the community alike.

From 2012 to 2013, a similar experiment was conducted in Mesa, Arizona, involving control and experimental groups. One hundred police officers from the Mesa Police Department were part of the study. Fifty officers were given cameras and the other 50 were not, and the results were similar to that of the Rialto study. There were nearly 3 
times more complaints against the officers who were not outfitted with the cameras than that of the officers who wore the technology, and a decline of complaints by more than $50 \%$ from pre-BWC to post-BWC implementation. The decline in use-of-force incidents was significant, at $75 \%$ for the officers who wore BWCs during their shifts. Lastly, a majority of both law enforcement officers and community members firmly believed the use of BWCs would improve community-law enforcement relations as well as provide better evidence for cases (Ohio Collaborative, 2015).

\section{Final opinion/conclusion}

Body-worn cameras, while still new and developing, are growing in popularity among the public and law enforcement agencies across the globe for many reasons. There are many perceived benefits to body worn cameras, which have been found in many if not all body-worn camera studies across the globe. There are multiple counter-arguments to the implementation of body-worn cameras, mainly over the issue that there are not enough studies done that conclude the technology is useful. While the benefits and positive influences of body-worn cameras is highly present in recent studies, the concerns must be addressed as well.

Many of these concerns have revolved around the privacy of citizens and police officers, but mainly citizens. Not only this, but also safety concerns, possibilities of increased police corruption, and abuse of power by police officers. Many civil liberties activists have proposed different policies to address these violations before they occur, namely by limiting police officer interference or say in what is to be recorded, and by urging law makers to review more thorough research on the effects of BWCs. The 
difficulty many law makers and law enforcement departments face is a lack of thoroughly tested ideas and studies done on the effects of BWCs. While there are many recorded studies and experiments with positive results, compared to many policies implemented, BWCs are one of the newest and least-known technologies in today's police force. With the explosion of technology and the fast-growing abilities of modern equipment, it is difficult to determine whether the improvements seen in law enforcement as a result of body-worn cameras will continue.

However, the many studies already conducted on the effects of BWCs has shown that the technology has great potential to positively influence law enforcementcommunity relations, the efficiency of the court system, and relieve overcrowding in prisons. Police departments that have experimented with using cameras have seen decreases in citizen complaints, use-of-force incidents, and caseloads for attorneys (fewer cases are going to trial). Furthermore, the video footage collected by officers wearing BWCs has provided better evidence for cases, and has been an exceptional tool in prosecuting domestic violence offenders, especially involving victims who are hesitant to testify.

Evidence supporting the implementation of BWCs in law enforcement does not just involve legal benefits and a reduction in complaints. Many polls and questionnaires given to samples of the public reveal a general support of BWCs, mainly because of their appeal to community-law enforcement relations and added protection of minorities. Not only this, but a majority of those in support of the technology were willing to pay more in taxes to outfit their local law enforcement agency with cameras. The willingness of the 
public to pay out of their own pocket for BWCs is a telling sign that the idea is seen as a positive addition to modern police forces in America.

Body-worn cameras can be a valuable addition to the equipment and technology used by law enforcement agencies across the nation, and based on the research found, will most likely continue as a useful tool in law enforcement. As a result of the information discovered through literary sources, news reports, and police databases, the technology proves to be a highly beneficial tool to law enforcement and the community. Body-worn cameras can protect both police officers and the public from wrongful accusations and provide evidence of events that occurred. The technology can speed up court proceedings, increase trust between officers and the community, and serve to increase the efficiency of the American criminal justice system. The perceived benefits and positive influences on recent studies prove that body-worn camera technology is a breakthrough technology that should continue in modern-day policing. 


\section{Sources:}

Body-Worn Camera Toolkit. (2015). Bureau of Justice Assistance: U.S. Department of Justice. Retrieved April 16, 2017, from https://www.bja.gov/bwc/pdfs/bwc_faqs.pdf.

Body Worn Cameras Policy - San Francisco - Revised 05/25/2016. (2016). Retrieved April 20, 2017, from https://www.bwcscorecard.org/static/policies/2016-0601\%20San\%20Francisco\%20-\%20BWC\%20Policy.pdf.

Cato Institute National Survey on Policing and Criminal Justice. (2015). Cato Institute. Retrieved May 11, 2017, from https://object.cato.org/sites/cato.org/files/wpcontent/uploads/bodycameras_010416.pdf.

Farrar, W. (2014, January 25). Operation Candid Camera: Rialto Police Department's Cody-Worn Camera Experiment. Retrieved April 20, 2017, from https://nationaluasi.com/dru/Operation-Candid-Camera-Rialto-PoliceDepartment\%E2\%80\%99s-Body-Worn-Camera-Experiment-012514

Fischer, C. (Ed.). (2014). Legitimacy and Procedural Justice: A New Element of Police Leadership. Retrieved March 15, 2016, from http://www.policeforum.org/assets/docs/Free_Online_Documents/Leadership/legi $\underline{\text { timacy }}$ and procedural justice - a new element of police leadership.pdf

Katz, Charles M., David E. Choate, Justin R. Ready, \& Lidia Nuño. (2014). Evaluating the Impact of Officer Worn Body Cameras in the Phoenix Police Department. Phoenix, AZ: Center for Violence Prevention \& Community Safety, Arizona State University. 
Koepke, L. (2015, June 24). Equal Future. The Mess That is Texas' New Body-Worn Camera Law. Retrieved May 11, 2017, from https://www.equalfuture.us/2015/06/24/texas-body-worn-camera-law/

Koepke, L. (2015, November 11). Equal Future. Leveling the Playing Field on Officer Review of Body Camera Footage. Retrieved May 12, 2017, from https://www.equalfuture.us/2015/11/11/leveling-the-playing-field-on-officerreview-of-body-camera-footage/

Miller, Lindsay, Jessica Toliver, and Police Executive Research Forum, 2014. Implementing a Body-Worn Camera Program: Recommendations and Lessons Learned. Washington, DC: Office of Community Oriented Policing Services.

Ohio Collaborative Community-Police Advisory Board. Office of Criminal Justice Services. October $2^{\text {nd }}, 2015$. Body Worn Camera Program. Retrieved May 21, 2017, from http://www.ocjs.ohio.gov/ohiocollaborative/links/Body-WornCamera-Program_The\%20Research.OC-Oct-2-meeting.pdf

Orenstein, W. (2016, January 15). Wash. Lawmakers Seek Rules for Police Body Camera Video. Retrieved February 1, 2016, from http://www.policeone.com/policeproducts/body-cameras/articles/64454006-Wash-lawmakers-seek-rules-forpolice-body-camera-video/

Ramirez, E. A Report On Body Worn Cameras. Retrieved May 21, 2017, from https://www.bja.gov/bwc/pdfs/14-005_Report_BODY_WORN_CAMERAS.pdf

Shepard, K. (2017, March 31). Conundrum Stalling Seattle's Body-Cam Policy. MyNorthwest.com. Retrieved May 12, 2017, from https://mynorthwest.com/587482/seattle-body-cam-policy-questions/

Stanley, J. (2015, March). Police Body-Mounted Cameras: With Right Policies in Place, a Win For All. Retrieved February 1, 2016, from https://www.aclu.org/policebody-mounted-cameras-right-policies-place-win-all

Stanley, J., \& Bibring, P. (2015, January 13). Should Officers Be Permitted to View Body Camera Footage Before Writing Their Reports? Retrieved May 12, 2017, from https://www.aclu.org/blog/free-future/should-officers-be-permitted-viewbody-camera-footage-writing-their-reports

White, Michael D. (2014). Police officer body-worn cameras: Assessing the evidence. Washington, DC: Office of Community Oriented Policing Services.

Winton, R., \& Mather, K. (2014, December 16). L.A. will buy 7,000 body cameras for police officers. LA Times. Retrieved February 1, 2016, from http://www.latimes.com/local/lanow/la-me-ln-mayor-to-announce-onbodycamera-rol-lout-for-lapd-20141216-story.html

Wolfe, E. (2016). The Unblinking Eyewitness: Should All Police Start Wearing Body Cameras? California Magazine. Retrieved February 1, 2016, from 
http://alumni.berkeley.edu/california-magazine/just-in/2014-12-30/unblinkingeyewitness-should-all-police-start-wearing-body 